\title{
ASENTAMIENTOS HUMANOS EN TORNO A LOS HUMEDALES DE LA CIUDAD DE VALDIVIA EN TIEMPOS PREHISPÁNICOS E HISTÓRICOS COLONIALES
}

\author{
HUMAN SETTLEMENTS AROUND THE WETLANDS OF VALDIVIA CITY \\ FROM PRE HISPANIC TO COLONIAL TIMES
}

\author{
Leonor Adán Alfaro ${ }^{1}$, Simón Urbina Araya y Margarita Alvarado Pérez ${ }^{3}$
}

\begin{abstract}
El presente trabajo analiza la ocupación humana en torno a los humedales de Valdivia, concentrándonos en los períodos alfareros prehispánicos e históricos hasta momentos finicoloniales. Se estudian, a partir de fuentes arqueológicas, documentales y cartográficas, las diversas estrategias y relaciones establecidas en estos paisajes del agua por poblaciones indígenas e hispanas, dando cuenta de la valoración ambivalente hacia los espacios de ciénagas y pantanos en la mentalidad hispana. Proponemos el inicio de un proceso de modificación sustantiva de la fisonomía urbana y zonas de humedales iniciada a fines del siglo XVIII por obras de infraestructura defensivas que definirán un momento inicial de transformación del paisaje, fortalecido durante el período Republicano.

Palabras claves: Arqueología de humedales, humedales históricos, Valdivia, Guadalafquén, cerco de Duce.
\end{abstract}

This paper presents an archaeological and historical characterization of human settlements around the wetlands of the city of Valdivia. It especially focuses on pre-Hispanic and historic ceramic periods until the end of the Spanish Colonial period. The different strategies and relations developed in these water landscapes by indigenous and Hispanic populations are studied from archaeological, documentary, and cartographic sources of information, revealing an ambivalent valuation of wetlands by Spaniards. We propose a process of massive modification of the colonial urban and wetland areas beginning in the last decades of the eighteenth century, through the construction of defensive buildings and bordering walls. This defines an initial moment of transformation of the wetlands zones within and around the city of Valdivia, which will be strengthened throughout the Republican period.

Key words: Wetland archaeology, historical wetlands, Valdivia, Guadalafquén, wall of Duce.

El estudio que presentamos profundiza en las relaciones humanas y ambientales en un tipo particular de ecosistema y paisaje definido como humedal para el caso de la ciudad de Valdivia $\left(39^{\circ}\right.$ Lat. S). Se sistematizan los registros arqueológicos analizando las particularidades en la ocupación de estos espacios y definiendo un modo de vida característico de las poblaciones locales desde tiempos prehispánicos mediante la identificación de un conocimiento geográfico particular, patrones en el asentamiento e indicaciones de valoración social y comunitaria de estos "paisajes del agua" (Skewes, Solari et al. 2012). Junto con lo anterior discutimos y abordamos la confrontación evidente que se hace en los períodos históricos entre los modos de vida y percepciones del paisaje entre la población local mapuche-huilliche y los vecinos hispanos que habitaron Valdivia, que resultará en transformaciones significativas por medio de obras de infraestructura urbana hacia fines del siglo XVIII.

\section{Arqueología de Zonas de Humedales}

El estudio de ambientes de humedales en Europa, Norteamérica, Centroamérica y otras regiones del mundo ha provisto significativos resultados, relevando la importancia del conocimiento del pasado en la definición e implementación de políticas (Dunning et al. 2013; Menotti y Sullivan 2013). Menotti y Sullivan han observado cómo las

1 Dirección Museológica, Universidad Austral de Chile. Casilla 586, Valdivia, Chile. ladan@uach.cl

2 Laboratorio de Arqueología, Dirección Museológica, Universidad Austral de Chile. Casilla 586, Valdivia, Chile. simon.urbina@uach.cl

3 Instituto de Estética y Centro Interdisciplinario de Estudios Interculturales e Indígenas (ICIIS). Pontificia Universidad Católica de Chile.malvarap@puc.cl 
aproximaciones de la wetland archaeology han aportado importantes resultados de investigación, a la vez que han enfatizado el rol social de la investigación arqueológica en la conservación y apropiación de estos ecosistemas.

En el territorio tradicionalmente ocupado por poblaciones mapuches, las investigaciones arqueológicas e históricas han destacado la estrecha relación de las comunidades humanas y sus ambientes a partir de enfoques ambientales, estudios etnográficos y mediante la caracterización de modos de vida singulares a períodos y territorios. Los estudios acerca de humedales son aún escasos en el Centro-Sur de Chile, contándose, no obstante, con importantes trabajos en el sistema estuarial de la desembocadura del río Biobío y cursos asociados (Quiroz 2010; Seguel 1969; Torres et al. 2007), la costa de Arauco (Contreras et al. 2005; Quiroz 2010), la zona de Purén-Lumaco (Dillehay 2011; Dillehay et al. 2007; Dillehay y Saavedra 2010) y la desembocadura del río Imperial (Dillehay et al. 2007; Van Meurs y Gordon 1989) (Figura 1).

En Purén-Lumaco las investigaciones han expuesto evidencias acerca de la transformación y creación de un paisaje cultural en torno a zonas de humedales (Dillehay 1985, 2011; Dillehay y Saavedra 2010). Dillehay ha planteado que la resistencia de sus poblaciones en tiempos históricos no habría sido solo la fiereza de sus guerreros y su organización política y religiosa, "sino la geografía de su inmenso sistema de pantanos que se expandía hacia un gran lago y una fortaleza invernal" (Dillehay 2011:161).

La costa de Concepción y el sistema estuarial que conforma fue estudiada desde los inicios de la arqueología científica (Seguel y Campana 1970). Las ocupaciones han sido analizadas teniendo en consideración las transformaciones geomorfológicas $\mathrm{y}$ variaciones ambientales locales, identificando una secuencia desde 6.500 años a.p. (Quiroz 2010; Quiroz y Sánchez 2004). Playa Negra-9, al sur de la ciudad de Penco, evidencia ocupaciones humanas reiteradas en un ambiente de humedales del estuario del Andalién con registros entre 3.800-3.300 años a.p. (Torres et al. 2007). El Arenal-1 constituye otro caso significativo (Contreras et al. 2010), similar a las pesquerías de tiempos históricos (Mariño de Lobera 1865 [1580]:215).

Por otra parte, la investigación ha comenzado a prestar atención a la relevancia de los cursos de agua y ambientes húmedos en los procesos socioeconómicos y políticos. El enfoque preferente hacia "tierra firme" comienza a ser ampliado a la comprensión de los cuerpos de agua en los procesos relacionales entre los grupos humanos y el paisaje. Una de estas aproximaciones es el propuesto por Bengoa que desarrolla la propuesta de la sociedad mapuche como una "sociedad ribereña", lo cual se expresaría en el asentamiento como en el sistema simbólico por la equivalencia establecida entre el futa leufu o gran río de la tierra y el huenu leufu o río celeste (Bengoa 2003:30). A su vez el análisis de la voz lebo con el cual se designa a una unidad básica de la estructura político-territorial mapuche ha sido relacionada con la de leufu o río (Boccara 2007:83). La navegación y embarcaciones indígenas cumplirían un rol fundamental y se distinguirían rutas fluviales, terrestres y mixtas, definiendo una espacialidad y movilidad organizada (Carabias et al. 2010; Lira 2010).

Otros indicadores que aportan información respecto de esta relación con ambientes acuáticos se evidencia en expresiones materiales empleadas por las poblaciones regionales. Uno de los casos más interesantes lo constituyen las representaciones anfibias que se conocen de la cerámica Pitrén, la más temprana a nivel regional (ca. 300 d.C.-1.000 d.C.) (cfr. Mera y Lobos 2008). En otro plano, se debe mencionar el empleo de especies de pajas o juncos como materia prima fundamental de la arquitectura local. En efecto, como lo señalan los análisis de sitios arqueológicos, fuentes históricas y estudios etnográficos, la habitación básica es caracterizada como pajiza, dando cuenta de la importancia de la accesibilidad a este recurso. Los diccionarios elaborados por Luis de Valdivia y Andrés Febres relevan la variedad de denominaciones para este valorado recurso. El primero destaca batu, enea, totora; quegi, cortadera; ranql, carrizo o caña; remu, juncos; y coliu, cañas, correspondiente a quilas y colihues. Febres a su vez informa del cùna o paja cortadera, gutan o coyrón, lin, la paja ratonera, rutho, cierta paja cortadera, además del carrizo (Adán 2014).

Desde nuestra aproximación, la relación de las comunidades humanas con estos ambientes húmedos y boscosos, como lo desarrollamos a continuación, expresa una mayor integración y complejidad que aquella posible de ser descrita desde perspectivas 


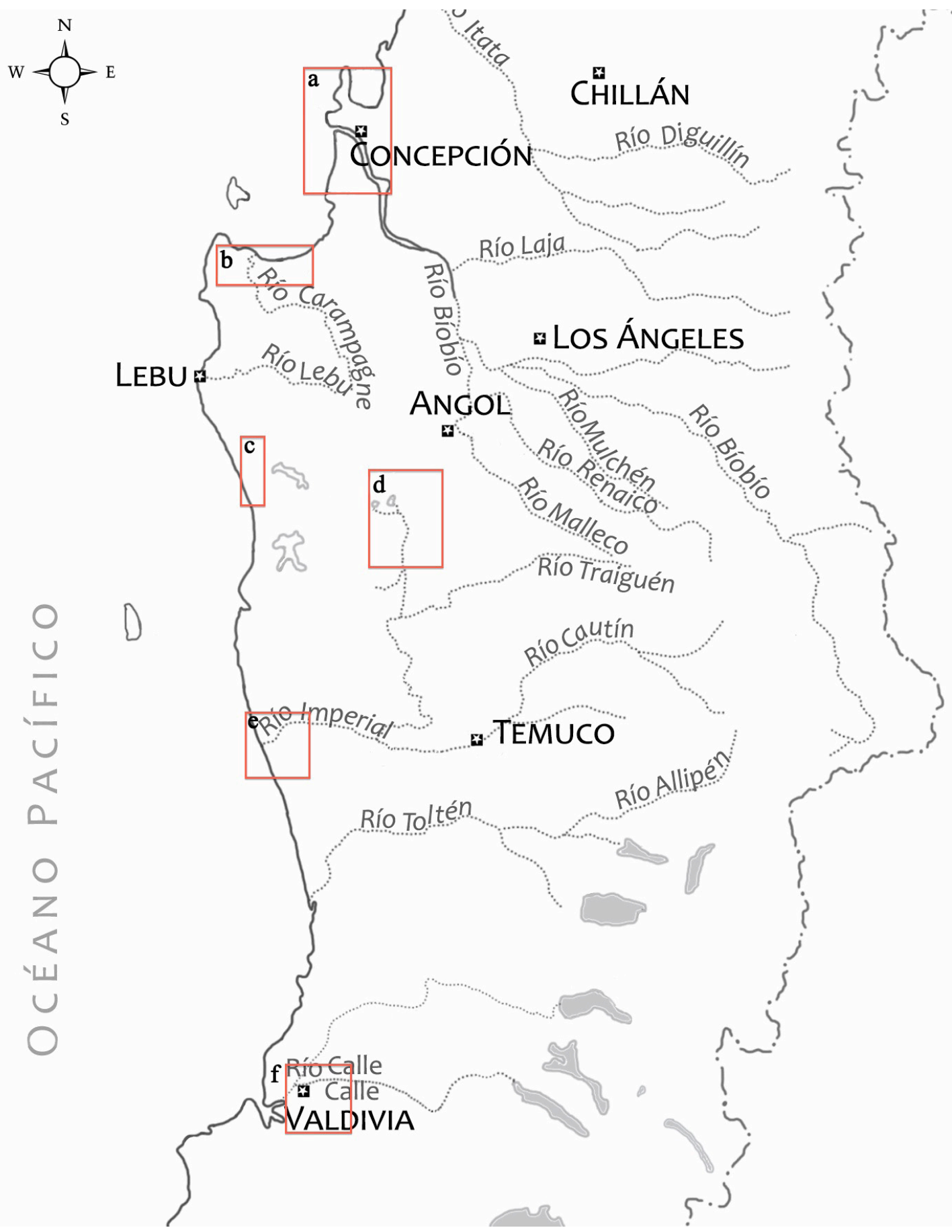

Figura 1. Zonas de humedales en la zona Centro Sur de Chile. Wetlands zones of South Central Chile. 
adaptacionistas propias de los enfoques ecológicoculturales que adoptó y desarrolló la Nueva Arqueología. Con anterioridad desarrollamos y propusimos la idea de una Tradición Arqueológica de Bosques Templados que expresaría la continuidad de prácticas y rasgos culturales de las poblaciones asentadas en los ecosistemas boscosos (Adán et al. 2010). En perspectiva, tal visión nos permitió fortalecer la idea de poblaciones de bosques que, si bien participaron de esferas culturales más amplias y adoptaron desarrollos innovados previamente en otras regiones, crearon una cultura y modo de vida en estrecha imbricación a sus ecosistemas, asentados y movilizándose en los mismos. Tal tesis buscaba superar la visión de los habitantes de estas latitudes como exploradores ocasionales de bosques inhóspitos y cerrados (cfr. Camus y Solari 2008). A su vez, el estudio de la región del Calafquén desde una perspectiva arqueo y etnoestética nos permitió identificar la configuración de topos activos del paisaje, las relaciones y cambios ocurridos a lo largo del tiempo con las comunidades humanas (Alvarado 2000).

En este trabajo avanzamos en la comprensión del territorio de Valdivia para los períodos históricos centrándonos en una cualidad fundamental de su configuración definida por el entorno fluvial y de humedales y las relaciones establecidas con las comunidades humanas originarias y aquellas europeas arribadas a mediados del siglo XVI. El estudio que planteamos se funda en la idea de que estos espacios del agua deben ser entendidos como agentes activos (Ingold 2011:121; Latour 2008:105110, 230-235), constituyendo un espacio que es denotado por poblaciones indígenas y europeas por esta cualidad sustantiva, la cual permite y hace posible una modalidad del asentamiento particular que emplea los materiales y condiciones locales, así como pone en tensión nociones y experiencias del paisaje.

\section{Valdivia en el Guadalafquén}

Las primeras descripciones hispanas de Valdivia destacaron, junto a la condición de su puerto, abundancia de poblaciones, cualidades de sus maderas y existencia de minas de oro, su emplazamiento en un magnífico río y la existencia de grandes porciones de agua. Una tierra "muy senegoza", llana y con algunas hoyas destacó Vivar (1979:188). Góngora y Marmolejo (1862 [1575]:30) describe "aquel valle, llamado Guadalauquén”. En los méritos del capitán Pedro de Olmos de Aguilera, la región se describe en 1574 como "provincia de Guadalafquén en el río que dicen de Valdivia" (Colección de Documentos Inéditos (CDI) Tomo XXV:31), mientras el vecino Gaspar de Villarroel expone sus derechos sobre el principal Gayquicheno de Guadalauquén (CDI Tomo XVI:454). Por último, Mariño de Lobera describirá el Guadalauquén como el río junto al que se pueblan (Mariño de Lobera 1865 [1580]:139).

La referencia a Guadalafquén es mencionada igualmente por el cronista mayor Antonio de Herrera, quien lo describe como una provincia entre Copiapó y el estrecho de Magallanes (Herrera 1601-1615, Década VII 1:12). Vásquez de Espinoza a su vez menciona Guadalafquén como un llano cercado de serranías hasta donde subía el mar (Vásquez de Espinosa 1948 [1636]:693), para luego insistir en su denominación como provincia. Miguel de Aguirre participante en la repoblación del siglo XVII reiterará la denominación como provincia (Aguirre 1923 [1647]:63-64).

En el siglo XVII Rosales abundará en esta denominación cuando describa a Valdivia como la "ciudad del Lago", señalando que lo que hace "mas celebre y deliciosa la planta de esta ciudad, es la hermosura y grandeza del rio, que la vaña, que tomando su origen de una laguna, que llaman Ruguigue". Al llegar a la Mariquina "muda el nombre, y con otros ríos que se le junta, se haçe un mar de modo, que le pusieron por nombre, Guadalabquen, que es nombre de mar" (Rosales 1989 [1674] Tomo I:408). La ciénaga que la cercaba hacia el oriente es llamada como Purento "cuio pantanoso obstáculo, le guarda las espaldas, dexandole dos passos angostos a los lados, que guardar al cuidado" (Rosales 1989 [1674] T I:409) ${ }^{1}$.

El plano holandés de Valdivia (ca. 1643) indica el río Guadalafquén, las trazas de la ciudad y el límite oriental cercado por el humedal ${ }^{2}$. Otras fuentes cartográficas destacarían Guadalafquén como una laguna -Ruyters en 1627-, o bien como provincia -Hessel Gerritsz 1630, Joannes Jansonnius 1647, Nicolas Sanson DÀbbeville 1656 y Guillaume Sanson en 1668 y 1669- (Guarda y Moreno 2010), en tanto los mapas del siglo XVIII de fray Ignacio León Garavito (1759) y Tomás López (1777) reiterarán la indicación de una provincia o región (Figura 2; Tabla 1). 

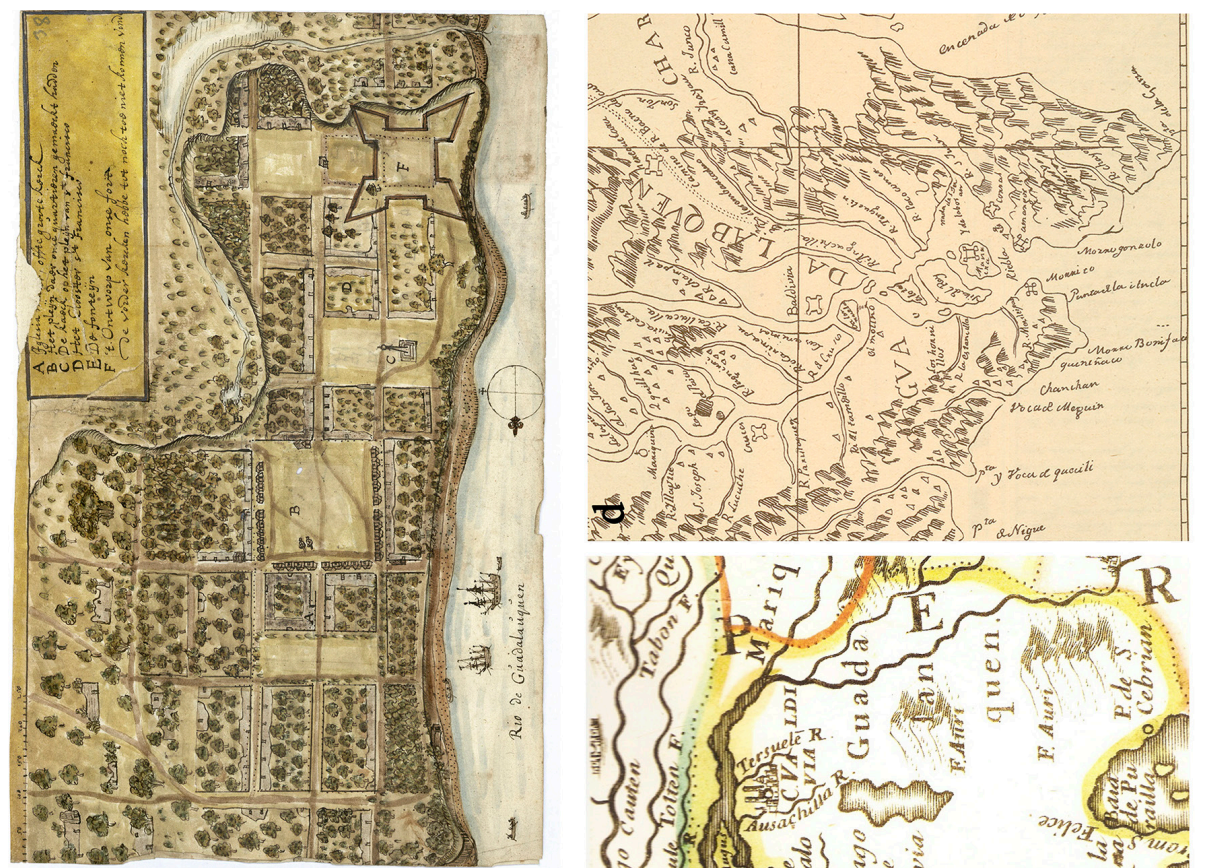

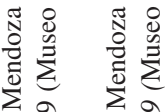

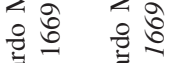

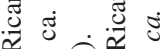

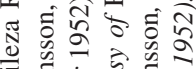

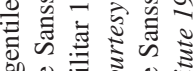

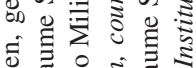

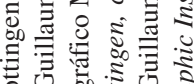

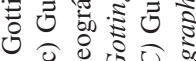

¿ (3)

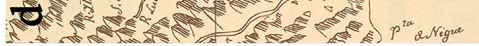

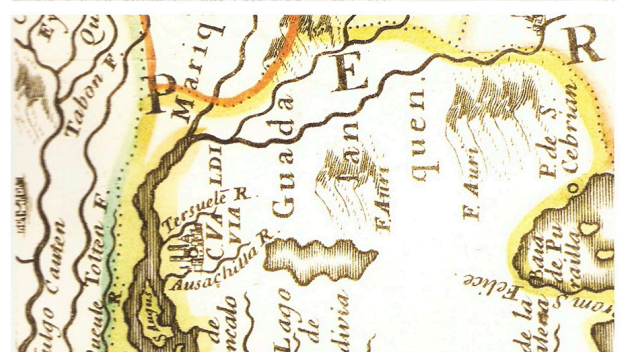
क人ิ

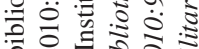

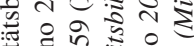

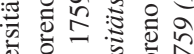

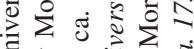

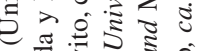

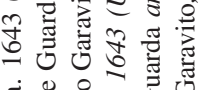

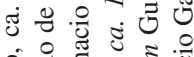

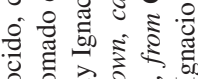

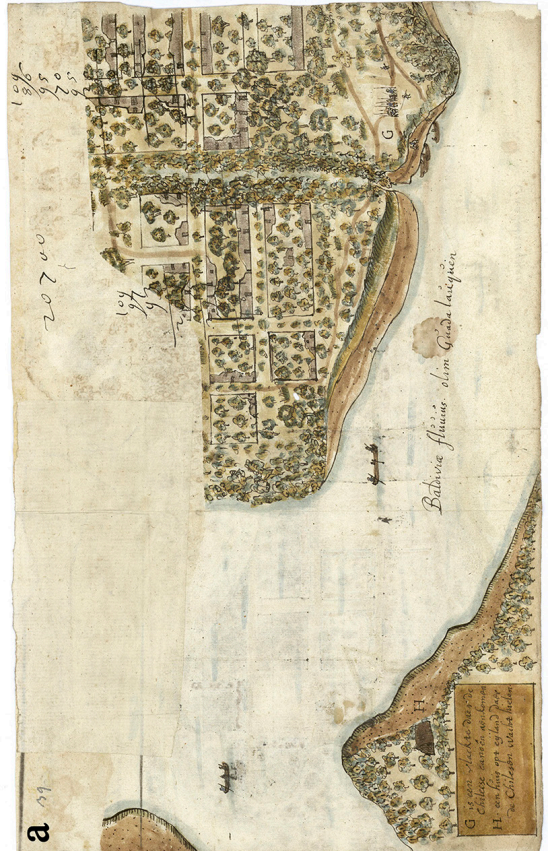
हin

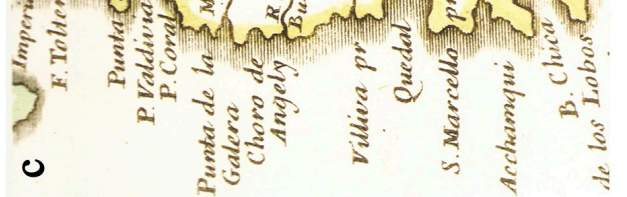

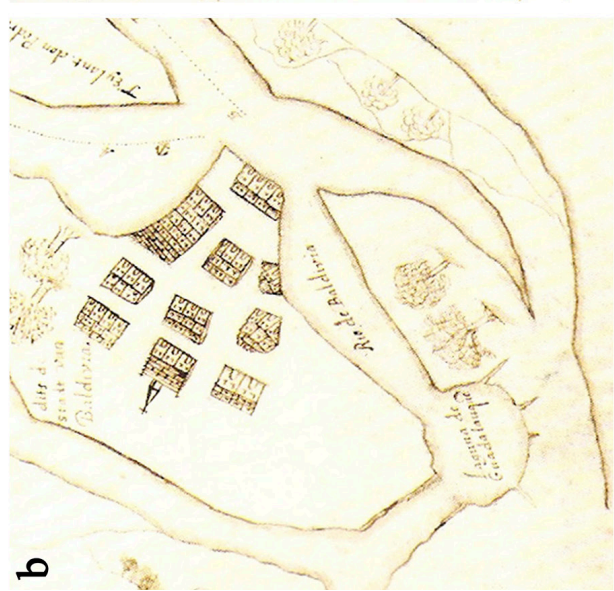
을

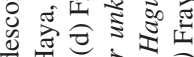
落药方令

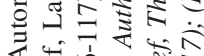

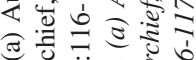

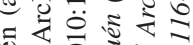

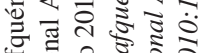

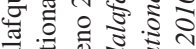

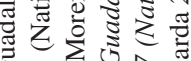
ป $\sum_{\lambda}$ ป 入े ฮี

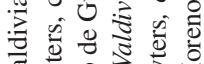

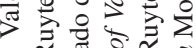

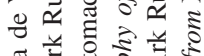

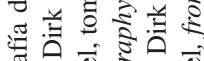
कृ

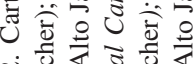
语范芯芯 


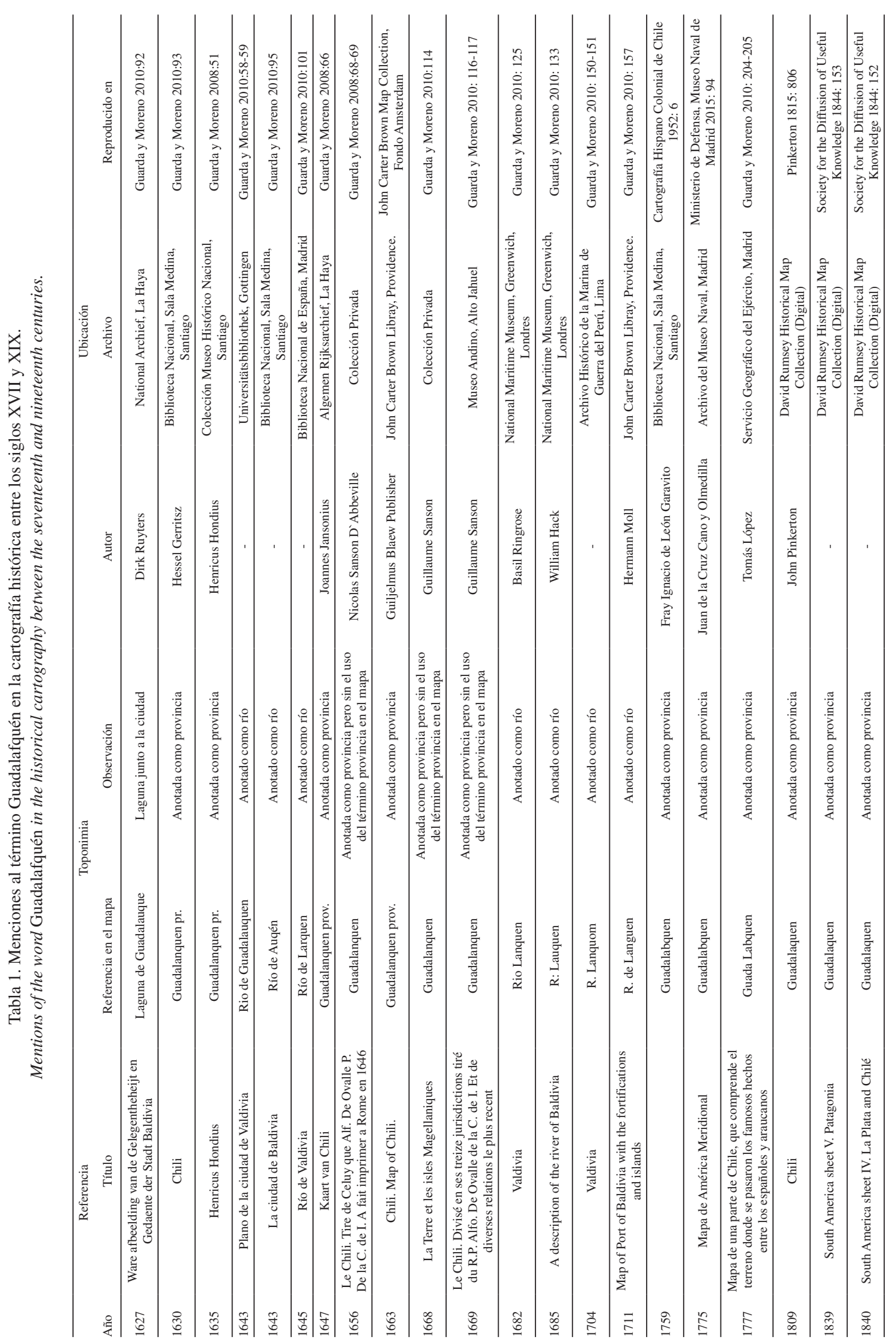




\section{Caracterización de los Humedales de Valdivia}

El estudio sistemático de la dinámica de los humedales actuales de Valdivia ha sido materia de reciente preocupación mayormente referida a su evolución durante el último siglo y en especial con posterioridad al terremoto de 1960 . Se ha analizado la vulnerabilidad y amenazas a las que se encuentran sometidos estos espacios hoy inscritos en la trama urbana, como a las estrategias de organización y revaloración por parte de vecinos y poblaciones circundantes (cfr. Osorio 2009; Paredes 2010; Rubilar 2002; Skewes, Rehbein y Mancilla 2012; Villagra y Felsenhardt 2015).

Los humedales se definen como biotopos "de composición y estructura compleja, de delicado equilibrio ecológico, localizados en zonas de transición entre sistemas acuáticos y terrestres, que sostienen vegetación hidrófita y mantienen substrato saturado de agua" (Rojas et al. 2015:182). En Valdivia se han reconocido como humedales aquellos ubicados en las riberas de los ríos asociados al estuario de carácter fluviopluvial e influencia marina, humedales interiores en depresiones de las formaciones de cancagua y de carácter pluvial, y otros en el borde occidental de la formación de piedra laja al NE de la ciudad de carácter freático-fluvial (Paredes 2010:8; Rubilar 2002) ${ }^{3}$. Skewes, Rehbein y Mancilla (2012:132) distinguen en la ciudad tres tipos de zonas húmedas: humedales en tanto sistema ecológico metapoblacional interconectado con características de corredor de especies, gualves o áreas deprimidas cerradas con límites tanto naturales como antrópicos, y vegas o planicies adyacentes a los cauces inundados según regímenes de marea.

La terminología en mapudungun acerca de los paisajes del agua es muy diversificada y compleja distinguiendo varias denominaciones para cursos de agua, acumulaciones de agua y zonas donde la humedad varía según la estación del año, el nivel de pluviosidad o el movimiento de las mareas. En este sentido, el conocimiento del mapuche de su territorio y condiciones lo llevó a hacer distinciones de acuerdo con su propia definición de humedad, topografía y vegetación. Así se enfatiza por ejemplo la diferencia entre menoko, como un pantano de forma redonda solo en su superficie, pero cuya principal característica es que puede tragarse los animales y las personas y kulpad o fotra, como un pantano, pero como un sitio barroso y de humedad extendida (Augusta 1966). En Augusta igualmente se menciona padañko mapu para designar terrenos húmedos y en Luis de Valdivia (1684) vna pedu para designar cieno. En el caso de Febres (1765) se identifica pantano con la voz chapad o ciénego como puthayghen, lodazal como pelentu, llod como cosa húmeda. La voz hualhualn o hualgaln se refiere a cómo hace murmullo el agua, o sonar gruñir las tripas, hacer gargarismo, o zangolotear lo líquido, hualihueyco, sonó el ciénego o el charco (Febres 1765). De acuerdo con Sánchez, el sustantivo gualve, incluido en el DRAE, se formaría a partir de estas voces y su significado como maizal no sería verosímil (cfr. Sánchez 2010:235). Notable es que el término entonces tenga relación con una cualidad sonora del paisaje y las posibles relaciones que establece con las representaciones zoomorfas que como hemos señalado se encuentran presentes en la cerámica regional desde el período Alfarero Temprano.

Otras distinciones significativas se efectúan al señalar los cursos de agua que surgen desde estos pantanos como llodkeñ mapu (Aug) referido al pantano que se forma desde donde bajan los chorrillos o bien ralonko (Aug) que se describe también como walfeko como agua que sale del pajonal o gualve. Otro conjunto de términos se refiere a las características vegetacionales de los mismos como Ranqlhue (Vald) que señalan cañaverales, o Molco (Meyer Rusca 1955) que señala un pantano cubierto de paja $\mathrm{mol}$.

En términos fluviales el asentamiento donde se fundó la ciudad forma parte de la hoya o cuenca hidrográfica del río Valdivia la cual se genera en territorio argentino conformando una hoya calificada como trasandina (Niemeyer y Cereceda 1984:182189; Subiabre y Rojas 1994:64-66). Dos grandes ríos conforman el río Valdivia en la ciudad misma, el Cruces de origen preandino y el río Calle-Calle resultado de un complejo sistema fluviolacustre. El Cruces se origina en la vertiente occidental de los cerros entre los lagos Villarrica y Calafquén; tiene un desarrollo total de $125 \mathrm{~km}$ de NE a SW, entre zonas con riberas acantiladas y otras meándricas que conforman islas y pantanos. Antes de su unión con el Calle-Calle en Valdivia recibe los aportes de los ríos Nanihue y Pichoy. El río Calle-Calle se origina de la unión de los ríos San Pedro y Quinchilca. El primero de estos es el emisario del lago Riñihue y de una cadena de lagos en serie: Lácar, Pirihueico, Neltume, Panguipulli y Riñihue. El Panguipulli recibe además en su ensenada septentrional al emisario del 
lago Calafquén, el río Huanehue. El Calle-Calle transita al W por cerca de $55 \mathrm{~km}$, conformando el Valdivia una vez que se une con el Cruces. Desde este punto el recorrido del Valdivia avanza $15 \mathrm{~km}$ para desembocar en la bahía de Corral, uniéndosele el río Tornagaleones por el oriente, el que a su vez es alimentado por los cursos de los ríos Angachilla y Futa, de breve desarrollo.

Los estudios respecto de las condiciones geomorfológicas, dinámica sísmica e inundaciones en la ciudad de Valdivia han sido trabajadas por
Rojas (2010) y Rojas y Diez (2013), lo cual permite modelar y proyectar la situación en tiempos pasados (Figura 3$)^{4}$. En términos geomorfológicos, la ciudad se encuentra emplazada en gran parte sobre una terraza de origen fluvial a una altura aproximada de $9 \mathrm{~m}$ sobre el río, la cual al menos desde 1552 no habría sido inundada. Esta terraza se levanta abruptamente desde los ríos o llanuras de inundación, con alturas que varían entre los 6 y 20 metros sobre estos. La conformación de la terraza es una arenisca con abundantes componentes de

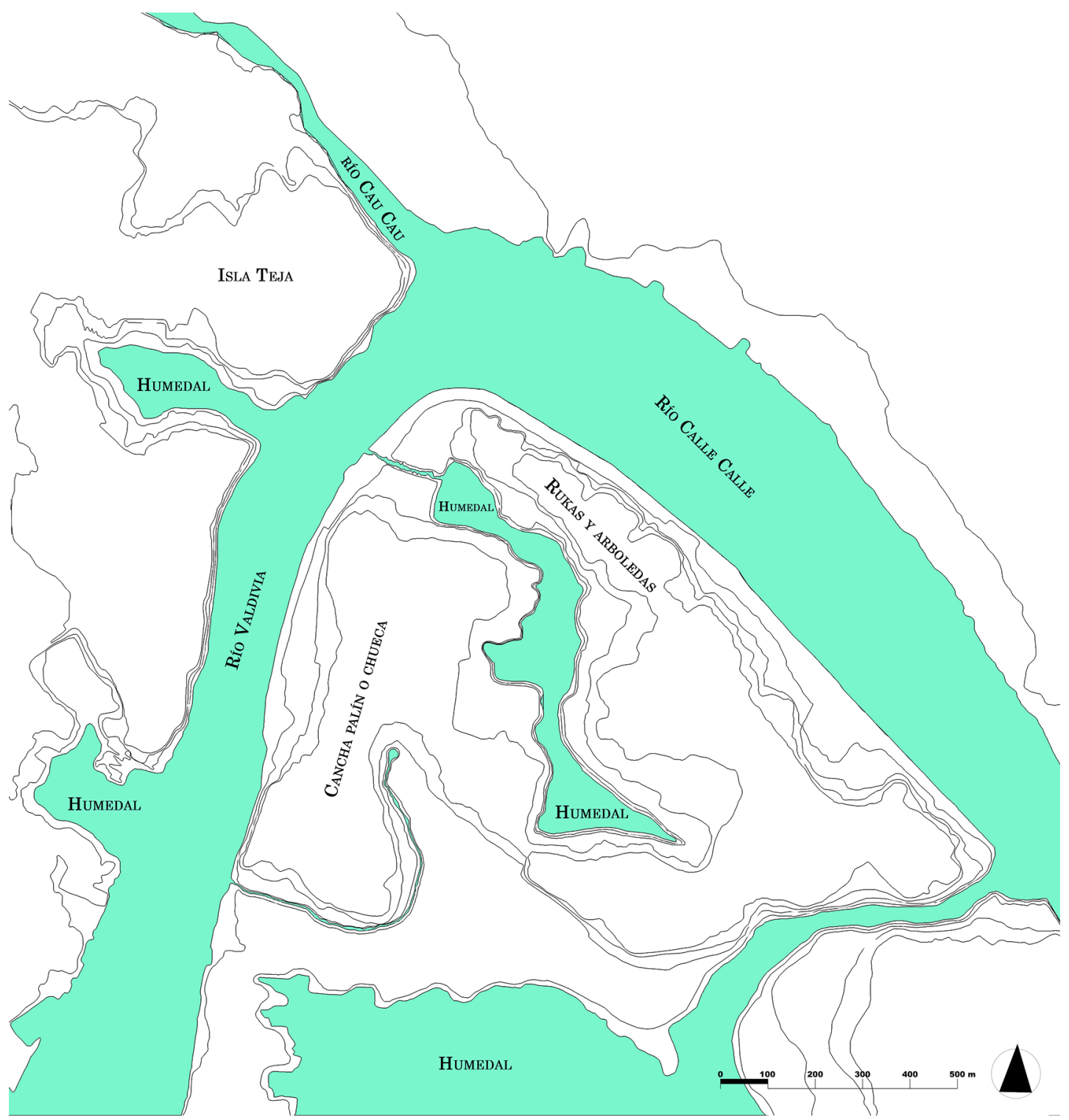

Figura 3. Modelamiento de humedales en torno al Área Fundacional de Valdivia basada en cartografía histórica (ca. 1643-1785). Model of wetlands around the Foundational Area of Valdivia based on historical cartography. 
origen volcánico denominada como cancagua. Los sectores localizados en cotas inferiores a los $2 \mathrm{~m}$ sobre el nivel del río corresponden a una llanura aluvial, presentan pendientes menores al 5\%, un nivel freático somero y alta humedad del suelo. Las terrazas aparecen delimitadas por escarpes con estas unidades geomorfológicas más bajas. En la porción sur y suroccidental de la ciudad estas terrazas presentan aspectos de mesetas separadas por sectores bajos sinuosos correspondientes a paleocauces tallados en terrazas ocupados por humedales interiores. Tanto estos sectores bajos interiores como los sectores ribereños del río Calle-Calle-Valdivia han sido objeto de rellenos artificiales en especial desde mediados del siglo XIX, a lo cual se suma el rebaje de la terraza del sector céntrico a principios del siglo XX (Rojas 2010; Rojas y Diez 2013).

\section{Asentamientos Históricos y Prehispánicos}

La historia arqueológica de Valdivia nos permite reconstruir con una perspectiva temporal amplia la modalidad del asentamiento que en ella tuvo lugar y la forma en que este se relaciona con la secuencia cronológica cultural de la región Centro Sur de Chile. Al analizar el asentamiento con posterioridad a la segunda mitad del siglo XVI, podemos añadir a las fuentes arqueológicas aquellas históricas, permitiéndonos cuestionar la fractura entre los llamados períodos prehistóricos e históricos. El detalle y conjunto de antecedentes arqueológicos que conocemos y hemos levantado para la ciudad de Valdivia han sido expuestos con detalle en otros trabajos, por lo cual acá se remite al lector a la lectura de dichos textos para mayor profundización.

La ocupación arqueológica de Valdivia cuenta con evidencias desde momentos Alfareros con algunas señales del período Arcaico. El período Arcaico regional cuenta con evidencias desde 10.000 años a.p. en la región cordillerana y en la costa norte de Valdivia a partir de 6.000 años a.p. Así es que ya para el Arcaico Medio y Tardío se reconoce una ocupación recurrente de diferentes ambientes por parte de poblaciones en contacto, como se juzga del patrón común para enterrar a sus difuntos. En el caso de Valdivia y el valle en general, el registro ha sido esquivo, lo cual se interpreta como resultado de sucesivos procesos de sedimentación (Adán et al. 2007:12). No obstante, algunas evidencias señalan la temprana ocupación de estos terrenos.
Menghin informa del hallazgo de una punta de proyectil tipo talcahuanense en el estero Naguilán (Menghin 1962:14). Se conocen, adicionalmente, hallazgos dispersos de material lítico característico del período en Huachocopihue, en el centro sur de la ciudad. En tercer lugar, se cuenta con la evidencia de un incendio datado hacia 4.400 años a.p. (Beta 24773) en el centro de la ciudad 5 .

La ocupación de la zona de Valdivia para el Alfarero Temprano se encuentra documentada en el sitio Santa María (Adán y Mera 1997), localizado en las riberas del río Cruces contiguo al humedal Santuario de la Naturaleza Carlos Anwandter. Se encuentra datado en $845 \pm 120$ d.C. (UCTL 888). Para el período Alfarero Tardío (ca. 1100-1552 d.C.) reconocemos una mayor frecuencia de registros, entre los que se cuentan asentamientos habitacionales, funerarios, y algunos probablemente de carácter congregacional. Un primer conjunto de asentamientos con componentes alfareros tardíos prehispánicos e históricos se localizan en el centro histórico o Área Fundacional, recurrentemente instalados en cotas altas cercanas a los cursos de agua tanto fluviales como de los humedales interiores (Figura 4; Tabla 2). Un grupo relevante de estos se emplaza en la loma septentrional, ribereña al Calle-Calle, correspondiente a aquella descrita por Mariño de Lobera. Al SW de esta porción de tierra se describe una "larguísima carrera de cuatrocientos pasos donde los indios jugaban a la chueca" (Mariño de Lobera 1865 [1580]:138), lo cual destaca la centralidad política y territorial del asentamiento (Urbina et al. 2016).

Otro conjunto relevante se encuentra en el perímetro urbano, distante del área central entre 3 y $6 \mathrm{~km}$. Se trata de los sectores de Cabo Blanco al norte del río Calle-Calle y Cau Cau y las zonas de Paillao y Angachilla al SE y SW. En Cabo Blanco se identifica un conjunto cerámico disperso propio de un sector habitacional emplazado en el sector alto de la terraza fluvial. Paillao, contiguo a zonas bajas húmedas, configura una superficie de $48.400 \mathrm{~m}^{2}$ con el registro de seis unidades discretas correspondientes a asentamientos habitacionales. En Angachilla, más al sur, se han reconocido conjuntos domésticos y destaca la ocurrencia de Las Mulatas-1 correspondiente a un cementerio con cerámica Valdivia.

Además de estas áreas acotadas conocemos hoy los resultados de una prospección sistemática efectuada en torno a la ciudad que permitió identificar un conjunto de 134 recursos arqueológicos. El 


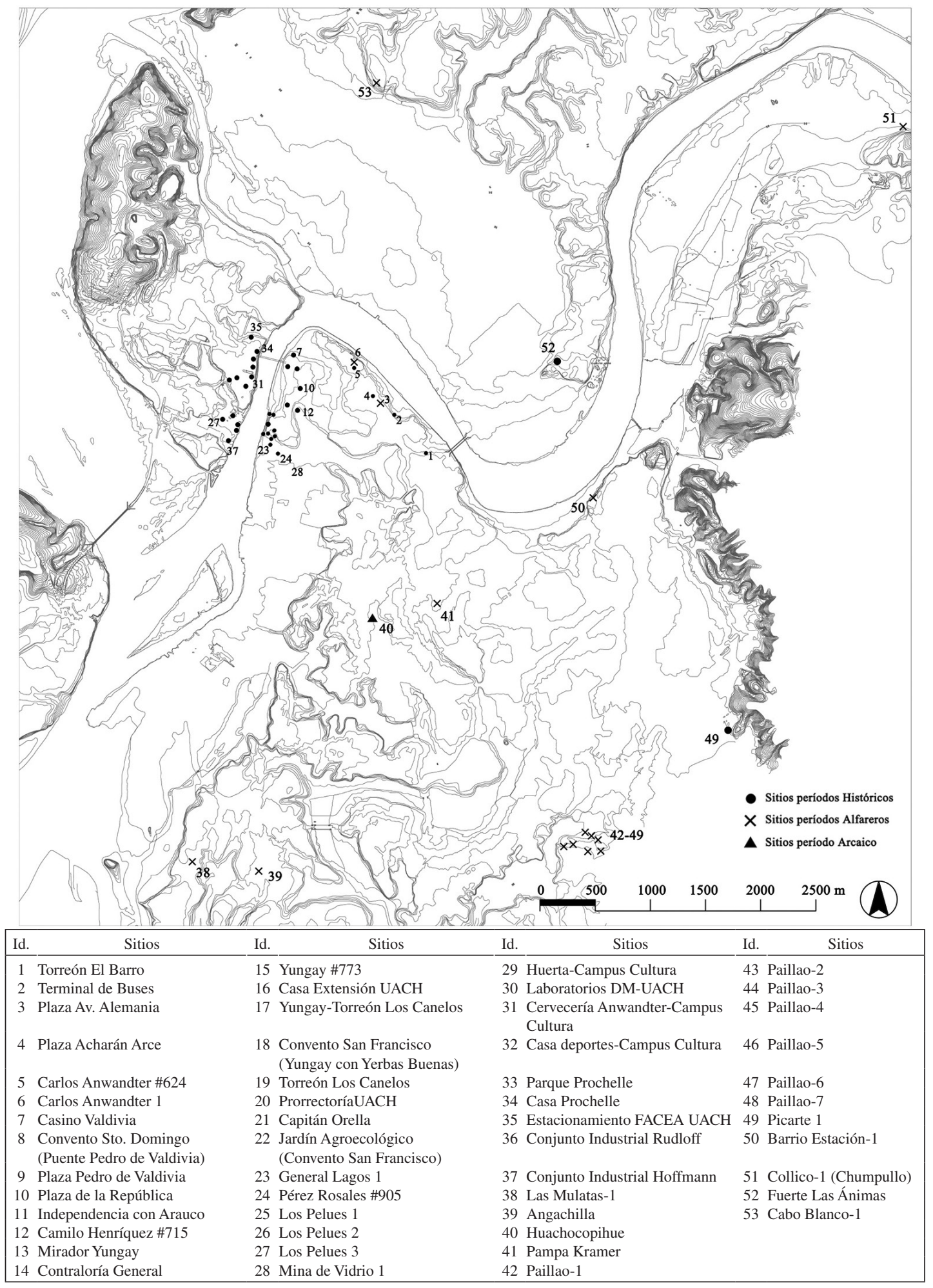

Figura 4. Mapa de localización e indicación de cronología de sitios arqueológicos en el Área Fundacional y Perímetro Urbano de Valdivia.

Location map and chronology of archaeological sites in the Foundational Area and Urban Perimeter of Valdivia city. 


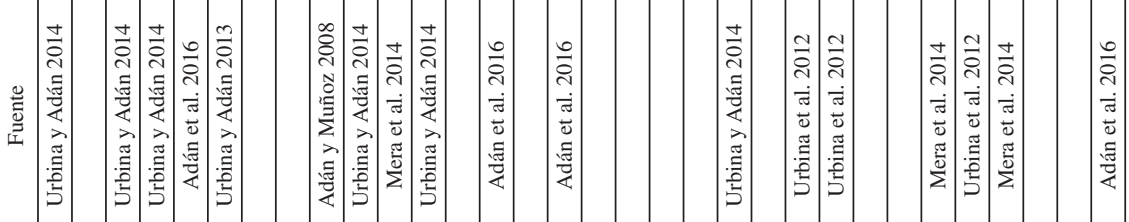

要要

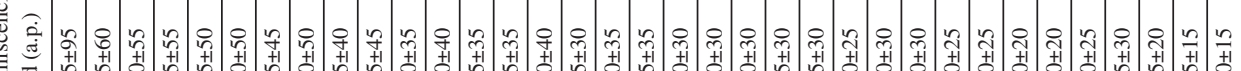

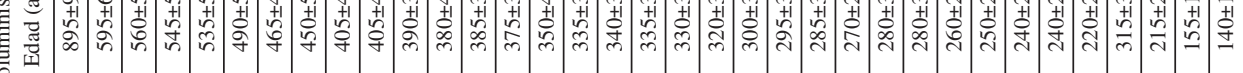

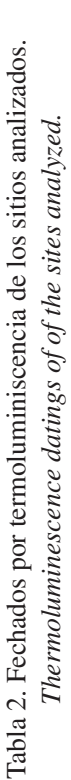

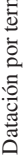

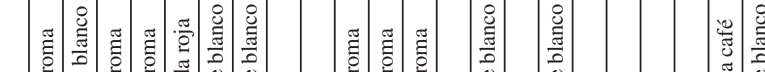

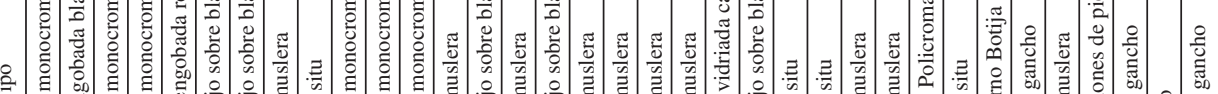

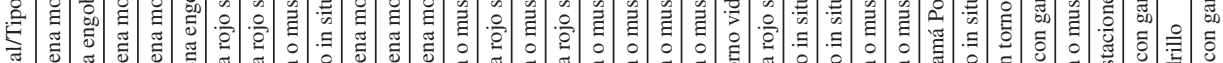

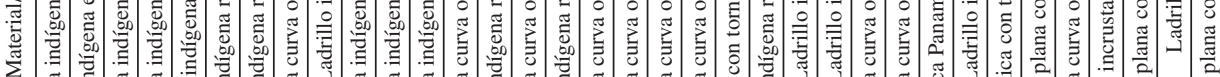

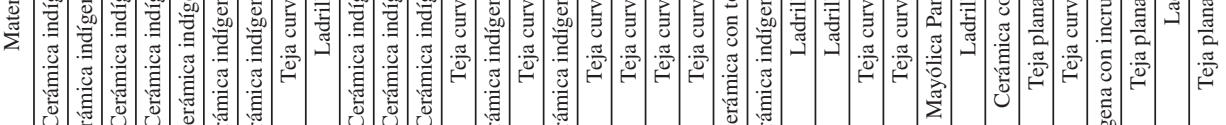
ชั 己े 己े

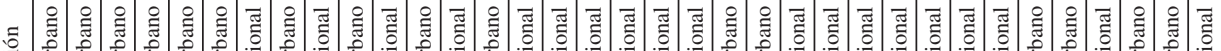
兽

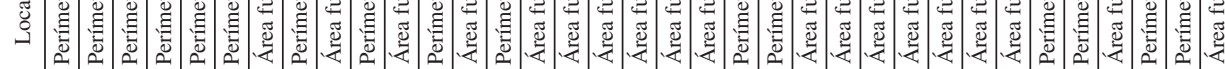

$\frac{\sqrt{2}}{0.0}$

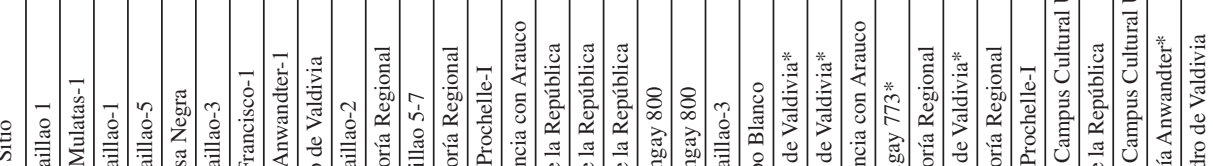

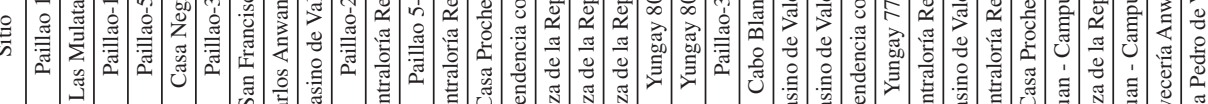

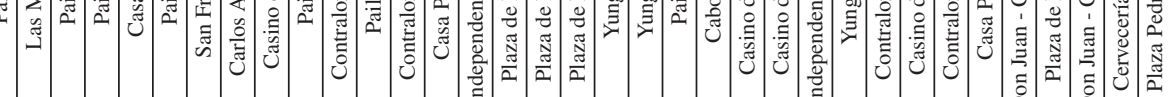

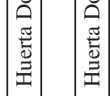

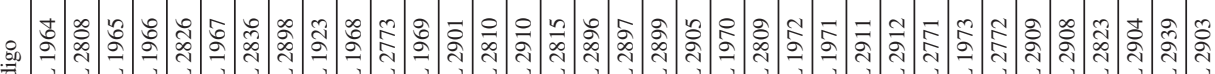

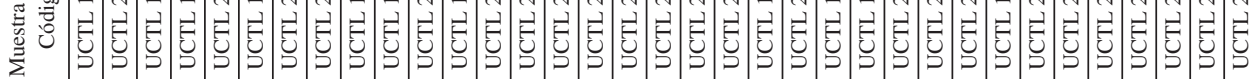


análisis, desde una perspectiva regional, que identificó nodos ocupacionales relevantes en los cuales se aplicó una metodología sistemática que permitiese validez comparativa, hizo evidente que de la jurisdicción de Valdivia colonial la mayor densidad de registros arqueológicos se encontró en Valdivia con 1,23 ra/km lineal ${ }^{6}$. De estos registros la totalidad corresponde a sitios de los períodos alfareros y cerca de $70 \%$ presenta una materialidad de cronología posthispánica. El 69\% de los registros se encuentra directamente asociado a terrazas fluviales y humedales y $24 \%$ a lomajes, cerros y aterrazamientos en altura (Munita 2016).

La fundación de la ciudad de Valdivia en 1552 reocupa espacios domésticos y ceremoniales del asentamiento indígena, como ocurre con la instalación de la Plaza e Iglesia Mayor sobre el palihue. Según lo observado en el plano holandés, la planta se conformaría por manzanas apaisadas que resultarían de la modificación de manzanas tradicionales subdivididas luego del terremoto de 1575 (Guarda 1994:25). La planta se acomoda a cotas altas y a la proximidad de cuerpos de agua (Figura 3 y 4). La ciudad aparece limitada al S y SE por un área baja y pantanosa, donde se ubica un cuerpo de agua denominado como Do fontë̈n, la fuente o vertiente (Figura 2a). En la porción $\mathrm{N}$ se señala la circulación de un curso de agua que sirvió de desagüe a los humedales interiores, dotado de un pequeño puente. La desembocadura de este curso se asocia al puerto fluvial en el lugar que hasta hoy ocupa la Feria Fluvial. Se aprecian además humedales ribereños en la ciudad y en la isla de Valenzuela (hoy Teja).

Distantes entre 1 a $4 \mathrm{~km}$ de la plaza encontramos un perímetro poblacional en el cual predominan conjuntos cerámicos de Tradición Indígena (Urbina y Adán 2014). Todos ellos se asocian espacialmente con zonas de humedales, señalando una característica del patrón de asentamiento indígena local que valora las posibilidades ecosistémicas ofrecidas por estos paisajes, tanto en contextos domésticos como rituales.

En el poema histórico de Arias de Saavedra se describe la celebración del triunfo indígena en un Reguetun con motivo de la recuperación de la ciudad, para lo cual "se salieron/Fuera de la ciudad a celebralla/En un florido prado que eligieron". Los festejos, sacrificios y tormentos ocurridos son observados por el teniente Andrés Pérez quien sobrevive "en un fangal en blando lodo". Cuatro días permanece el militar "desde el pantano a donde oculto estaba", vertiendo sangre por diecisiete partes "Pero cuando se vió ya desangrado/ En cieno de la ciénaga se baña/Y con aquesta cura la restaña". Termina este trance para el teniente "Del pantano salió medio pasmado/ A gatas, que los pies se le entumieron/A la playa llegó desfigurado/ En el navío al fin le recogieron" (Arias de Saavedra 1984:643-645).

La refundación de la ciudad en 1647 se acota al sector alto de la terraza, ocupando tan solo 1,9 hectáreas, a diferencia de las 13 hectáreas de la fundación. La plaza murada se emplaza entre dos cursos de agua que desaguaban las lagunas interiores, al $\mathrm{N}$ el tradicional catrico y al $\mathrm{S}$ el curso que permitía la circulación del gualve de San Antonio. Como señalaba Rosales, el sitio quedaba al oriente defendido por la ciénaga mientras que el río Valdivia y el Calle-Calle "vienen a ser muralla cristalina que cercan la ciudad" (Rosales 1989 [1674] Tomo I:409). Entre 1645 y 1750 ocurriría la explotación de los terrenos inmediatos, siendo la chacra su exponente más significativo (Guarda 1973:7-16). Las ocupaciones se instalan en torno a los dos caminos que articulan la ciudad, ambos con denominaciones que acusan su disposición por terrenos anegadizos; en dirección W-E El Barro o Cantarranas y con orientación N-S Los Canelos (Figura 4, Tabla 2).

La expansión de la ciudad y sucesivos conflictos con las poblaciones indígenas de los Llanos estimularon la construcción de dos torreones en los caminos principales previamente señalados. Terminadas las obras se observaría su inutilidad sin edificar un cerco continuo, encargado al ingeniero Antonio Duce. Los planos que se conocen del diseño e implementación de esta muralla o cerco datan de 1780 y tienen el mérito de representar el diseño de una de las primeras obras arquitectónicas de envergadura que buscaría un control del curso de las aguas y una modificación sustantiva del paisaje urbano. El cerco pretendía aprovechar las aguas del pantano, desviando las aguas del río Calle-Calle al Valdivia "transformando el meandro y la ciudad en una isla inexpugnable" (Guarda 1990:103-105).

El informe de Duce de 1785 informa que tales modificaciones tenían por objeto proteger a la Plaza de los "indios bravos", implicando "excavación y escarpe", ya que si bien la plaza constituía un "pequeño cuadrilongo de simple muralla de piedra y 
lodo", quedaba "fuera todo el pueblo en los contornos del recinto, y con bastante separación unos de otros por miedo de los incendios" 7 . Como se aprecia en el plano, para su resguardo sería preciso correr una línea de defensa que en el sector NE o perfil AB se efectúa mediante "un pequeño frente cavando el terreno y quedando entre este y la contraescarpa su foso", faltando solo un parapeto de tepes. Hacia el río Valdivia se continuó la línea con el escarpe "siguiendo en parte las irregularidades del terreno, y en parte cortando líneas con redientes del mismo terreno sin dejar de flanquearse para defender las subidas del escarpe caso de superar los atolladeros del pantano que tiene por delante".

A continuación se estableció "un malecón o dique de tierra", el cual atravesó un brazo del pantano con el fin de evitar su retorno "tienen delante de sí el mayor y más ancho atolladero del pantano, y para más imposibilitar el acceso al malecón se le ha hecho a su pie una excavación de 8 varas de ancho y una de profundo: Fáltale el parapeto de tepes como en las demás líneas". La parte final, contigua al torreón, "se manifiesta un corto frente que cierra y finaliza la línea contra la orilla del río, donde por estar el terreno fangoso y arenisco necesita cerrarse lo inmediato al río con palizada". La obra total comprendería 2.400 varas de extensión, aproximadamente dos kilómetros, en todos "sus retornos y ángulos"".

\section{La Categoría de Ciénaga o Pantano en la Visión Hispana}

Fray Miguel de Aguirre describe la reocupación de la plaza de Valdivia en 1645 -luego de medio siglo de abandono- por el gobernador Gil de Negrete acuartelándose la gente en el sitio antiguo del convento de San Francisco. Los españoles observan las ruinas y el bosque crecido sobre la planta. El propio gobernador encomienda a su hijo Florián Gil de Negrete la exploración del lugar por temor a "emboscadas de indios". Con 50 hombres "caminando adelante hasta una ciénega que está en la ciudad, reconocieron cerca della unas huellas de indios, a quienes no pudieron hallar ni seguir" (Aguirre 1923:79). Las sospechas son fundadas y se sucede un encuentro bélico a favor de los hispanos, retirándose los indígenas "huyendo a la montaña y desamparando la campaña" (Aguirre 1923:80).

El relato antecedente da cuenta de la valoración de los españoles hacia estos ambientes, temidos por su fragosidad y que homologan al sitio y modo de vida de las poblaciones locales. En efecto, ciénagas y pantanos constituyen topos y espacios recurrentemente mencionados en las fuentes como parte de una connotación discursiva que destaca el carácter salvaje y agreste del territorio y las poblaciones locales, actuando como opuesto al llano civilizado, conquistado y ocupado por los españoles (Adán 2014:101). Góngora y Marmolejo reitera este sistema de oposiciones, relatándonos la desesperación de los mapuche ante la tierra llana de Andelicán en la cual ven tantos estandartes hispanos que "viéndose perdidos se llegaron a una ciénega, y en ella se hicieron fuertes; porque el lugar lo era de suyo para jente desnuda" (Góngora y Marmolejo 1862 [1575]:75). El recorrido narrativo del autor expresa fehacientemente la oposición llano-español/ ciénaga-gente desnuda.

Sin lugar a dudas la más famosa de estas ciénagas es Purén. Numerosas referencias señalan sus cualidades, como Arias de Saavedra, quien afirma que "Son los purenes gente belicosa/ En una gran laguna cenagosa/ viven, toda cercada de pantanos/ Arauco y Tucapel se les sujetan/ Y las demas provincias le [s] respetan" (Arias de Saavedra 1984:138). Fray Diego de Ocaña observa que es esta "la mayor fuerza que tienen en este Reyno porque es una laguna grande, muy hondable y con muchas islas dentro en las cuales habitan los yndios y con canoas se sirven" (Ocaña 1995 [1600]:38).

El caso de la ciudad de Valdivia, como el de otros asentamientos distribuidos en el territorio mapuche, pone en tensión estas nociones y busca el acomodo a estos paisajes que pese a su "mala fama" son habitados por numerosas poblaciones locales, sus campos religiosos las valoran y los mantenimientos e inclusive recursos constructivos básicos forman parte de estos dominios anegadizos. Guarda (1965) ha destacado parte de los preceptos que orientaron la instalación de los asentamientos urbanos como las Nuevas Ordenanzas de Descubrimiento, Población y Pacificación de las Indias de 1573 que establecen que las nuevas poblaciones debían elegir tierras saludables, con buenas entradas y salidas para comerciar, con agua cerca, pero en lugares no muy altos, "ni en lugares muy bajos, porque suelen ser enfermos" (Solano 1996:201). Como señala el estudioso, la redacción de tales ordenanzas fue influenciada preferentemente por preceptos desarrollados por Tomás de Aquino (Solano 1996:34-35). 
En el Tratado del Gobierno de los Príncipes se establece que "El lugar saludable, según Vegecio, será levantado, sin nieblas, ni muchas lluvias, que tenga el Cielo ni muy caluroso, ni muy frio, y que no tenga junto a sí lagunas ni pantanos". La sutileza del aire fue igualmente asunto de importancia, ya que "que importa mucho para la libre y descansada respiración, se impide con las nieblas y lluvias, de que suelen ser muy abundantes los lugares húmedos". Es así que, los "lugares pantanosos, y en que hay lagunas, son demasiado húmedos, convienen, que el que se escojiere, para fundar la Ciudad, sea apartado de pantanos y lagunas" (Aquino 1786:49).

Tales antecedentes nos permiten plantear que, si bien la fundación de la ciudad de Valdivia atiende gran parte de los aspectos de la ordenanza-densidad poblacional, cercanía al agua, accesos y relación con un puerto-, su emplazamiento junto a una zona de humedales enfrentó a sus nuevas poblaciones a un espacio temido por lo inhóspito y dificultoso para el control y dominio. El conocimiento de las formas de vida indígena y la incorporación de tecnologías que hacían habitables estos territorios y se beneficiaban de las zonas de humedales -recursos, canoas monóxilas, material constructivo y prácticas arquitectónicas-, propiciaron una valoración ambivalente de los paisajes húmedos, vistos como pródigos y peligrosos.

\section{Conclusiones}

El estudio que hemos presentado nos permite avanzar en el conocimiento de la historia del asentamiento en la zona de Valdivia, la variabilidad del asentamiento en territorio mapuche y ambientes boscosos, como también evidenciar el rol activo del paisaje, su agencia, y la forma en cómo este interactúa con visiones y nociones distintas propias del contexto intercultural indígena e hispano. Consecuentemente hemos podido documentar la condición nodal de Valdivia, la trayectoria del uso del término Guadalafquén al modo de una provincia identificable, la historia ocupacional del área con los diferentes modos de asentamiento y el cambio significativo que impone la ocupación hispana al paisaje a fines del siglo XVIII cuando se inician obras públicas de envergadura para drenar y ordenar la circulación del agua en torno a la ciudad. Por último, documentamos visiones en tensión acerca de estos paisajes del agua y antiguos preceptos europeos que se enfrentaron a aquellas nociones y prácticas del modo de vida local igualmente profundas temporalmente y evidentes en la distribución y organización del asentamiento.

Una primera constatación es cómo la localización de la ciudad de Valdivia constituye un área nodal en el contexto de un paisaje fluvial predominante. Tal condición geográfica es un asunto absolutamente relevante en consideración a las estrategias de movilidad fluvial de momentos prehispánicos e hispano-indígenas. La presencia de un área de juntas o eventos congregacionales identificada como un palín releva esta cualidad. Como sabemos, la fundación de la ciudad ocurrió comprometiendo el área de junta descrita y otra de asentamientos domésticos indígenas bien consolidada. Valdivia, en este contexto, se configura como un nodo espacial y poblacional pues actúa como un lugar de convergencia y articulación de personas y bienes.

Por el río Cruces, la ciudad se articula con regiones septentrionales y andinas hacia el Villarrica y el sistema de lagos vecinos, como también la costa bien poblada del Toltén. En dirección W-E el curso del río Calle-Calle conectó con un sistema poblacional ribereño, conectando luego hacia sectores cordilleranos del lago Ranco y cuenca del río Bueno, este último definiendo un eje bioceánico. El río Futa, por su parte, integra una ruta hacia los Llanos, camino revalorado en el siglo XVIII con los fuertes de Huequecura, del Pilar y San Fernando. Lo anterior, en consecuencia, define un paisaje de humedales en un contexto fluvial y marítimo, y que en tal sentido es también diferente a otras regiones dominadas por humedales. Estas condiciones ambientales y paisajísticas, así como la imbricación en el modo de vida local, otorgó a Valdivia y el Guadalafquén una relevancia y centralidad política y territorial, evidente en la población existente, de interacción y movilidad.

A su vez, esta connotación fluvial y abundante en aguas, sean estas ríos, esteros, lagunas o pantanos, se señala como un territorio distinguible que recibe la denominación de Guadalafquén. La trayectoria en el uso del término que hemos podido identificar mediante fuentes históricas señala la forma en cómo el área fue referida tempranamente al modo de una provincia sobre la cual ejercer un dominio (cfr. Cisterna 1999); luego, mencionada en documentos de la administración hispana títulos de encomiendas 
y pleitos entre encomenderos, historias y crónicas locales del siglo XVI, para ser retomada a comienzos del siglo XVII en crónicas reales y adoptada, con posterioridad, en la representación cartográfica de la expansión holandesa. En la cartografía holandesa, especialmente interesada en el control de este puerto, se observan en la primera mitad del siglo XVII, por una parte, denominaciones de hitos específicos como la laguna del Guadalafquén de Ruyters (ca. 1627) y el río del mismo nombre en la planimetría de la ciudad levantada en 1643. Para la segunda mitad del siglo XVII la cartografía releva la condición de una provincia amplia. Durante el siglo XVIII salvo algunos antiguos mapas holandeses de las primeras décadas, la voz se revalorizará en los mapas de fray Ignacio León de Garavito (ca. 1759) y de Tomás López (ca. 1777), que mantienen su connotación de provincia. Durante la primera mitad del siglo XIX vemos el topónimo Guadalafquén incluido en cartografías publicadas en textos de divulgación en Gran Bretaña como el Atlas Mundial de John Pinkerton y en los volúmenes de mapas de la Society for the Diffusion of Useful Knowledge (SDUK).

La distribución de sitios y evidencias arqueológicas describe una ocupación de la zona desde los períodos precerámicos, con un aumento de la intensidad ocupacional en los períodos Alfarero Tardíos (ca. 1100-1552 d.C.). Los registros prácticamente dibujan la topografía de aquellas épocas, con los asentamientos ocupando las porciones ribereñas fluviales y asociadas a los humedales. En estos lugares se constata la presencia de espacios domésticos asociados a sus áreas productivas, como también espacios rituales y congregacionales. Diversas líneas de evidencia disponibles para el área Centro Sur de Chile, destacan el uso de tecnologías que aprovecharon las características de estos ecosistemas, como los medios y técnicas de navegación y las prácticas constructivas que inclusive construyeron en barbacoas o palafitos como se documenta en Purén (Adán 2014:171173). Elementos iconográficos representados en la alfarería temprana relevan la valoración de especies de anfibios y aves, propias de ámbitos fluviales y humedales.

En el caso de Valdivia, lo que hoy entendemos como el Área Fundacional, la ocupación ocurrió en dos porciones o lomas alargadas, una en dirección WE, al norte, en la cual se describe un asentamiento organizado en torno a arboledas "sembradas a mano" y otra en dirección NS, en la porción occidental donde se conoce la presencia de un campo ceremonial, muy próximo al ojo o afloramiento acuífero identificado en la cartografía histórica. El curso de agua o catrico que se identifica en el plano holandés y que corre en dirección EW para desembocar en el río Valdivia, permitiría la circulación desde una laguna interior. No es descartable que este haya sido manejado en tiempos prehispánicos tal como se encuentra registrado para la zona de Purén (cfr. Olaverría en Gay 2009:5; González de Nájera 1889 [1614]:48).

Con todo, planteamos que durante los primeros 50 años de ocupación hispana (ca. 1552-1604) se ocuparon solares, edificaciones religiosas y públicas, plazas y el perímetro que mencionamos. La planta habría integrado estas zonas anegadizas sin obras mayores salvo pequeños puentes. Según Rosales, quien escribe en el siglo XVII, el diseño de la ciudad habría protegido sus frentes por los ríos y hacia el oriente por un gran Purento. La fuente de agua, como en el caso indígena, se asociaría al espacio público. En la repoblación la Plaza y Presidio de Valdivia durante la segunda mitad del siglo XVII fue acotada entre los dos cursos de agua que circulaban desde los humedales interiores y con el afloramiento igualmente a cercana distancia. Es con el estrechamiento de la Plaza y la necesidad de ampliar el espacio habitable, paralelo a la expansión de la ocupación de la ciudad hacia el interior y una serie de conflictos con las poblaciones indígenas que se emprende la primera gran obra de modificación del paisaje. Se trata del Cerco de Duce entre ambos torreones que además de implicar una obra de envergadura en términos de la modificación del paisaje como del concurso de gentes y recursos, significó simbólicamente imponer un deslinde fijo que separaba el área habitada del espacio que comprometía al pantano. Las obras para ganar terrenos donde antes estuvieron los humedales en el sector central de la ciudad se iniciaron a mediados del siglo XIX, intensificándose en el siglo XX (Guarda 1994).

De este modo, vemos que durante todo el período hispano-indígena colonial opera en la mentalidad y práctica hispana una valoración que aprecia positivamente estos espacios a la vez que les teme, por su distancia con el territorio civilizado y llano y su cercanía con el modo y territorio indígena, fragoso y doblado. Las formas de habitar estos paisajes, el estrecho contacto entre poblaciones indígenas, hispanas y criollas, fomentaría esta aproximación bivalente a los espacios de humedales, dando 
cuenta del rol activo del paisaje y los procesos de interculturalidad generados en las ciudades y sus entornos en los espacios meridionales de Chile.

Agradecimientos: Estudio realizado en el marco del proyecto FONDECYT 1130730
"Arqueología histórica de la ciudad de Valdivia y su jurisdicción en el período colonial". Consejo de Monumentos Nacionales Órdenes No 249 (2009) y $\mathrm{N}^{\circ} 2312$ (2015). Agradecemos las observaciones y comentarios de los evaluadores que nos permitió mejorar el manuscrito.

\section{Referencias Citadas}

Adán, L. 2014. Los Reche-Mapuche a Través de su Sistema de Asentamiento (Siglos XV-XVII). Tesis para optar al grado de Doctora en Historia, mención Etnohistoria, Departamento de Ciencias Históricas, Universidad de Chile, Santiago.

Adán, L., C. García y R. Mera 2010. La Tradición Arqueológica de Bosques Templados y su estudio en la región lacustre cordillerana de las regiones IX y X. Actas del XVII Congreso Nacional de Arqueología Chilena, Valdivia. Vol. II, pp. 14611471. Ediciones Kultrún, Valdivia.

Adán, L. y R. Mera 1997. Acerca de la distribución espacial y temporal del Complejo Pitrén. Una revaluación a partir del estudio sistemático de colecciones. Boletín de la Sociedad Chilena de Arqueología 24:33-37.

Adán, L., R. Mera, F. Bahamondes y S. Donoso 2007. Síntesis arqueológica de la cuenca del río Valdivia: proposiciones a partir del estudio de sitios alfareros prehispánicos e históricos. Revista Austral de Ciencias Sociales 12:5-30.

Adán, L. y S. Muñoz 2008. Rasgos arquitectónicos arqueológicos del proyecto inmobiliario y recreativo portal Valdivia comuna Valdivia, región de Los Ríos. Informe histórico arqueológico y recomendaciones de uso y conservación. Consejo de Monumentos Nacionales, Santiago.

Adán, L., S. Urbina, C. Prieto, V. Zorrilla y L. Puebla 2016. Variedad y comportamiento del material cerámico de tradición hispana e indígena en la ciudad de Valdivia y su jurisdicción entre los siglos XVI y XVIII. En Primeros Asentamientos Españoles y Portugueses en la América Central y Meridional s. XVI y XVII, compilado por L.M. Calvo y G. Cocco, pp. 251-272. Universidad Nacional del Litoral, Santa Fe.

Aguirre, M. 1923 [1647]. Poblacion de Baldivia. Motivos y Medios para Aquella Fundación. Colección de Historiadores de Chile y Documentos relativos a la Historia Nacional, Tomo XLV. Imprenta Universitaria, Santiago.

Alvarado, M. 2000. Vida, muerte y paisaje en los bosques templados. Un acercamiento a la estética del paisaje en la región del Calafquén. Aisthesis 33:198-216.

Aquino, T. de. 1786. Tratado del Gobierno de los Príncipes del Angélico Doctor Santo Thomas de Aquino. Traducido por Alonso Ordóñez das Sejas y Tobar. Imprenta de Benito Cano, Madrid.

Arias de Saavedra, D. de 1984. Purén Indómito. Edición crítica de Mario Ferreccio Podestá. Biblioteca Nacional, Universidad de Concepción, Santiago.

Astaburuaga, F.S. 1899. Diccionario Geográfico de la República de Chile. Santiago de Chile, Santiago.
Augusta, F.J. de 1966. Diccionario Araucano-Español y EspañolAraucano. Editorial San Francisco, Padre Las Casas-Temuco.

Bengoa, J. 2003. Historia de los Antiguos Mapuches del Sur. Desde Antes de la Llegada de los Españoles y las Paces de Quilin. Catalonia, Santiago.

Bernales Lillo, M. 1984. Aspectos diacrónicos de la toponimia de Valdivia. Anales de la Universidad de Chile $5^{\text {a }}$ Serie, Vol. 5:71-94.

Boccara, G. 2007. Los Vencedores. Historia del Pueblo Mapuche en la Época Colonial. Instituto de Investigaciones Arqueológicas y Museo de la Universidad Católica del Norte, Universidad de Chile, Santiago.

Camus, P. y M.E. Solari 2008. La invención de la selva austral. Bosques y tierras despejadas en la cuenca del río Valdivia (Siglos XVI-XIX). Revista de Geografía Norte Grande 40:5-22.

Carabias, D., N. Lira y L. Adán 2010. Reflexiones en torno al uso de embarcaciones monóxilas en ambientes boscosos lacustres precordilleranos andinos, zona Centro-Sur de Chile. Magallania 38:87-108.

CEA-CONAMA 2006. Protección y Manejo Sustentable de Humedales Integrados a las Cuencas Hidrográficas. Comisión Nacional de Medio Ambiente. Gobierno de Chile. Santiago.

Cisterna, P. 1999. El enunciado provincia en el ámbito de la conquista y la colonización Hispana. Revista Chilena de Humanidades 5:97-124.

Colección de Documentos Inéditos para la Historia de Chile 1852-1930 (CDI). Primera Serie. 30 Volúmenes. Imprenta Ercilla, Santiago.

Contreras, L., D. Quiroz, M. Sánchez y C. Caballero 2005. Ceramios, maíces y ranas... Un campamento El Vergel en las costas de Arauco. Actas del XVI Congreso Nacional de Arqueología Chilena, pp. 357-367. Sociedad Chilena de Arqueología, Concepción.

Dillehay, T. 1985. Cuel: Observaciones y Comentarios sobre los Túmulos en la Cultura Mapuche. Chungara Revista de Antropología Chilena 16-17:181-93.

Dillehay, T. 2011. Monumentos, Imperios y Resistencia en Los Andes. El Sistema de Gobierno Mapuche y las Narrativas Rituales. Qillqa, Universidad Católica del Norte, Universidad de Vanderbilt, Ocho Libros Editores, Santiago.

Dillehay, T., M. Pino, R. Bonzani, C. Silva, J. Wallner y C. Le Quesne 2007. Cultivated wetlands and emerging complexity in South Central Chile and long distance effects of climate change. Antiquity 81:949-960. 
Dillehay, T. y J. Saavedra 2010. Uso humano de humedales en las regiones de la Araucanía y el bosque valdiviano y en la costa Norte del Perú: tres casos históricos. Actas del XVII Congreso nacional de Arqueología Chilena, Vol. II, pp. 1509-1514. Ediciones Kultrún, Valdivia.

Dunning, N.P., T. Beach, L. Grasiozo Sierra, J. Jones, D. Lentz, S. Luzzader-Beach, V. Scarborough y M. Smyth 2013. A tale of two collapses: Environmental Variability and cultural disruption in the Maya lowland. Dialogo Andino 41:71-183.

Febres, A. 1765. Arte General de la Lengua del Reyno de Chile, con un Dialogo Chileno-Hispano muy Curioso, y Por Fin un Vocabulario Hispano-Chileno, y un Calepino Chileno-Hispano mas Copioso. Calle de la Encarnación, Lima.

Gay, C. 2009. Historia Física y Política de Chile. Documentos. Biblioteca Fundamentos de la Construcción de Chile, 3 Volúmenes. Cámara Chilena de la Construcción, Pontificia Universidad Católica de Chile, Dirección de Bibliotecas, Archivos y Museos, Santiago.

Góngora y Marmolejo, A. de 1862 [1575]. Historia de Chile desde su Descubrimiento hasta el Año de 1575. Colección de Historiadores y de Documentos Relativos a la Historia Nacional, Vol. II. Imprenta del Ferrocarril, Santiago.

González de Nájera, A. 1889 [1614]. Desengaño y Reparo de la Guerra del Reino de Chile. Imprenta Ercilla, Santiago.

González, M., M. Amoroso, A. Lara, T. Veblen, C. Donoso y T. Kitzberger 2014. Ecología de disturbios y su influencia en los bosques templados de Chile y Argentina. En Ecología Forestal. Bases para el Manejo Sustentable y Conservación de los Bosques Nativos de Chile, editado por C. Donoso, M. González y A. Lara, pp. 411-502. Ediciones Universidad Austral de Chile, Valdivia.

Guarda, G. 1965. Santo Tomás de Aquino y las fuentes del urbanismo indiano. Boletín de la Academia Chilena de Historia 72:5-50.

Guarda, G. 1973. La Economía de Chile Austral antes de la Colonización Alemana: 1645-1850. Universidad Austral de Chile, Valdivia.

Guarda, G. 1990. Flandes Indiano. Las Fortificaciones del Reino de Chile 1541-1826. Ediciones Universidad Católica de Chile, Santiago.

Guarda, G. 1994. Valdivia. Una Ciudad Chilena del Siglo XVI. Ediciones de la Universidad Católica de Chile, Santiago.

Guarda, G. 2001. Nueva Historia de Valdivia. Ediciones Universidad Católica de Chile, Santiago.

Guarda, G. y Moreno, R. 2008. Monumenta Cartographica Chiloensia. Corporación Patrimonio Cultural de Chile, Santiago.

Guarda, G. y R. Moreno 2010. Monumenta Cartographica Valdiviensae. Misión, Territorio y Defensa. Corporación Patrimonio Cultural de Chile, Santiago.

Herrera, A. de 1601-1615. Historia General de los Hechos de los Castellanos en las Islas i Tierra Firme del Mar Océano Escrita por Antonio de Herrera Coronista Mayor de su Majestad de las Indias y Coronista de Castilla. Imprenta Real, Madrid.

Heusser, C.J. 1994. Paleoindians and fire during the late Quaternary in southern South America. Revista Chilena de Historia Natural 87:435-443.
Ingold, T. 2011. Being Alive. Essays on Movement, Knowledge and Description. Taylor and Francis Group, Routledge, Londres.

Instituto Geográfico Militar 1952. Cartografía Hispano Colonial de Chile. Homenaje del Ejército de Chile a JT Medina. Sala Medina Biblioteca Nacional, Santiago.

Latour, B. 2008. Reensamblar lo Social. Una Introducción a la Teoría del Actor-Red. Ediciones Manantial, Buenos Aires.

Lira, N. 2010. Canoas Monóxilas en el centro-sur de Chile: navegando sobre los árboles. Actas del XVII Congreso Nacional de Arqueología Chilena, Vol. II, pp. 1473-1485. Ediciones Kultrún, Valdivia.

Mariño de Lobera, P. 1865 [1580]. Crónica del Reino de Chile. Colección de Historiadores y de Documentos Relativos a la Historia Nacional, Vol. VI. Imprenta del Ferrocarril, Santiago.

Menghin, O. 1962. Estudios de Prehistoria Araucana. Centro de Estudios Prehistóricos, Imprenta Mercur, Buenos Aires.

Menotti, F. y A. O’Sullivan 2013. Introduction Part I. Wetland occupations: A geographical and chronological perspective. En The Oxford Handbook of Wetland Archaeology, editado por O’Sullivan, pp. 1-6. Oxford University Press, Oxford.

Mera, R. y G. Lobos 2008. Anfibios y reptiles en el imaginario cultural de Chile. En Herpetología de Chile, editado por M.A. Vidal y A. Labra, pp. 55-76. Science Verlag, Santiago.

Mera, R., S. Urbina y D. Munita 2014. Rescate arqueológico en la obra Construcción edificio sede contraloría regional valdivia, región de los ríos. Informe final. Consejo de Monumentos Nacionales, Santiago.

Meyer Rusca, W. 1955. Diccionario Geográfico Etimológico Indígena de las provincias de Valdivia, Osorno y Llanquihue, con la colaboración del R.P. Ernesto Wilhelm de Möesbach. Imprenta San Francisco, Padre Las Casas, Temuco.

Ministerio de Defensa de España 2015. Dueños del Mar, Señores del Mundo. Historia de la Cartografía Náutica Española. Museo Naval de Madrid, Madrid.

Minsheu, J. 1617. Vocaublarium Hispanicum Latinum et Anglicum copiossisimum, cumnonnullis vocum millibus locupletatum, ac cum Linguae Hispanica Etymologijs [...]. Joanum Browne, Londres.

Munita, D. 2016. Reporte de resultados de prospección. Sitio Nodal Plaza de la República de Valdivia. Informe Técnico Fondecyt 1130730. Manuscrito en posesión de los autores.

Niemeyer, H. y P. Cereceda 1984. Geografía de Chile. Tomo VIII, Hidrografía. Instituto Geográfico Militar, Santiago.

Ocaña, D. de 1995 [1600]. Viaje a Chile. Relación del Viaje a Chile, Año de 1600. Editorial Universitaria, Santiago.

Osorio, F. 2009. Impacto del Crecimiento Urbano en el Medio Ambiente del Humedal de Valdivia 1992-2007. Tesis para optar al grado de Magíster en Asentamientos Humanos y Medio Ambiente. Facultad de Arquitectura y Estudios Urbanos, Pontificia Universidad Católica de Chile, Santiago.

Paredes, D. 2010. Determinación de Amenazas en Humedales Urbanos: Estudio de Tres Humedales de Valdivia, Chile. Trabajo de Titulación para optar al Título de Ingeniera en Conservación de Recursos Naturales. Facultad de Ciencias Forestales y Recursos Naturales, Universidad Austral de Chile, Valdivia. 
Pinkerton, J. 1815. A Modern Atlas. Cadell and Davies, Londres.

Quiroz, D. 2010. Ocupaciones El Vergel en las costas septentrionales de la Araucanía: una secuencia cronológica por termoluminiscencia. Actas del XVII Congreso Nacional de Arqueología Chilena, Vol. I, pp. 441-450. Ediciones Kultrún, Valdivia.

Quiroz, D. y M. Sánchez 2004. Poblamientos Iniciales en la Costa Septentrional de la Araucanía (6.500-2.000 a.p.). Chungara Revista de Antropología Chilena, Vol. Especial 36:289-302.

Rojas, C. 2010. Valdivia 1960. Entre Aguas y Escombros. Ediciones Universidad Austral de Chile, Valdivia.

Rojas, C. y S. Diez 2013. El Terremoto chileno del 27 de febrero de 2010: análisis preliminar de las consecuencias en la ciudad de Valdivia. Investigaciones Geográficas 60:139-153.

Rojas, C., E. Sepúlveda-Zúñiga, O. Barbosa, O. Rojas y C. Martínez 2015. Patrones de urbanización en la biodiversidad de humedales urbanos en Concepción metropolitano. Revista de Geografía Norte Grande 61:181-204.

Rosales, D. de 1989 [1674]. Historia General del Reino de Chile. Flandes Indiano, 2 Volúmenes. Editorial Andrés Bello, Santiago.

Rubilar, H. 2002. Estudios de los Humedales Urbanos de la Ciudad de Valdivia. Tesis de para optar al grado de Licenciada en Ciencias Biológicas, Facultad de Ciencias, Universidad Austral de Chile, Valdivia.

Sánchez, G. 2010. Los mapuchismos en el DRAE. Boletín de Filología XLV(2):149-256.

Seguel, Z. 1969. Excavaciones en Bellavista, Concepción. Actas del V Congreso Nacional de Arqueología, pp. 327-250. Museo Arqueológico de La Serena, La Serena.

Seguel, Z. y O. Campana 1970. Las Oscilaciones Glacio-Eustáticas Marinas Holocénicas y la Ocupación del Litoral Chileno entre los Ríos Andalién y Tubul en las Provincias de Concepción y Arauco. Planteamiento de una Cronología Relativa. Instituto de Antropología, Universidad de Concepción, Concepción.

Skewes, J.C., M.E. Solari, D. Guerra y D. Jalabert 2012. Los paisajes del agua: naturaleza e identidad en la cuenca del río Valdivia. Chungara Revista de Antropología Chilena 44:299-312.

Skewes, J.C., R. Rehbein y C. Mancilla 2012. Ciudadanía y sustentabilidad ambiental en la ciudad: la recuperación del humedal Angachilla y la organización local en la Villa Claro de Luna, Valdivia. EURE 38(113):127-145.

Society for the Diffusion of Useful Knowledge (SDUK) 1844. Maps of the Society for the Diffusion of Useful Knowledge, Vol. 1. Chapman and Hall, Londres.
Solano, F. de 1996. Normas y Leyes de la Ciudad Hispanoamericana 1492-1600. Biblioteca de Historia de América, Consejo Superior de Investigaciones Científicas, Madrid.

Subiabre, A. y C. Rojas 1994. Geografía Física de la Región de Los Lagos. Ediciones Universidad Austral de Chile, Valdivia.

Terreros y Pando, E. 1787. Diccionario castellano con las voces de ciencias y artes y sus correspondientes de las tres lenguas francesa, latina e italiana. Tomo segundo (abril), http://ntlle.rae. es/ntlle/SrvltGUILoginNtlle (30 agosto 2016).

Torres, J., C. Silva y M. Lucero 2007. El rol de la pesca en la intensificación de las ocupaciones costeras durante el Holoceno Medio-Tardío (Bahía de Concepción, Región del Bío-Bío, Chile). Magallania 35:71-93.

Urbina, S. y L. Adán 2013. La ciudad de Valdivia y su jurisdicción: elementos para una Historia Indígena en el período Colonial Temprano. Actas V Congreso Nacional de Arqueología Histórica Argentina, Tomo II, pp. 175-203. Universidad de Buenos Aires, Buenos Aires.

Urbina, S. y L. Adán 2014. Avances en la arqueología de Valdivia. Boletín de la Sociedad Chilena de Arqueología 43/44:35-60.

Urbina, S., L. Adán, R. Mera y D. Munita 2016. Fundación y refundación de Valdivia (Lat. S 39º): Implicancias arqueológicas de dos modalidades de instalación hispana (ca. 1552-1647). En Primeros Asentamientos Españoles y Portugueses en la América Central y Meridional s. XVI y XVII, compilado por Luis María Calvo y Gabriel Cocco, pp. 303-326. Universidad Nacional del Litoral, Santa Fe.

Urbina, S., L. Adán, D. Munita y R. Mera 2012. Arquitectura arqueológica y sitios patrimoniales sin arquitectura en el perímetro urbano de Valdivia: cartografía descriptiva actualizada y comentarios sobre su valor científico integral. Revista AUS 12:4-9.

Valdivia, L. de 1684. Arte y Gramatica General de la Lengua que Corre en todo el Reyno de Chile, con vn Vocabulario, y Confessonario. Thomás Lopez de Haro, Sevilla.

Villagra, P. y S. Felsenhardt 2015. El paisaje urbano de emergencia en Valdivia, Chile: Contribuciones a la planificación y el diseño urbano post-desastre para la restauración. Revista INVI 83:19-76.

Van Meurs, M. y A. Gordon 1989. Monkul-1: un conchal precerámico en el Centro-Sur de Chile. Chungara Revista de Antropología Chilena 23:19-36.

Vásquez de Espinosa, A. 1948 [1636]. Compendio y Descripción de las Indias Occidentales, editado por Ch. Upson Clark. Smithsonian Institution, Washington.

Vivar, G. 1979 [1558]. Crónica y Relación Copiosa y Verdadera de los Reinos de Chile (1558). Edición de L. Sáez-Godoy. Coloquium Verlag, Berlín. 


\section{Notas}

1 En relación con el significado de la palabra Guadalafquén, hemos registrado diversas menciones desde el siglo XVI en adelante que refuerzan su relación con el agua y la grandeza de esta. Su traducción literal como voz mapuche permitió a autores como Astaburuaga proponer que unifica la voz guada, calabaza o zapallo, con la de lauqén, el mar (Astaburuaga 1889:290), línea que sigue Valderrama, Meyer Rusca y Bernales Lillo para indicar que la voz señalaría "estuario en cuyas orillas se cultivan zapallos" (Bernales Lillo 1984:86). La voz guada o huada no es consignada en el Arte y Gramática de Luis de Valdivia, mientras que Febres lo añade como huada, calabaza o calabazo y huadahue, calabazal (Febres 1765:503). A su vez la voz guada en español corresponde a una voz de origen árabe que designa ríos y agua corriente, como se indica en el Vocabulario de Minsheu (1617). Terreros y Pando señala "Guada, palabra Arabe, lo mismo que agua viva, corriente, como rio, arroyo, V. De aquí salen las voces de ríos, y lugares de España, que empiezan con esta voz; y asi, Guadalajara, quiere decir rio en jara; y según otros, en piedras..." (Terreros y Pando 1787, Tomo II:243) (Consultado en http://ntlle.rae.es/ntlle/ SrvltGUILoginNtlle).

2 Universidad de Gottingen, Alemania. Ha sido reproducido en Guarda (1994, 2001) y Guarda y Moreno (2010).

3 Existen diferentes definiciones de humedales vigentes, dependiendo del enfoque y empleo que se le dará a esta definición (CEA-CONAMA 2006:5). Una de las más usadas es aquella de la Convención de Ramsar que en su artículo $1^{\circ}$ establece que "son humedales las extensiones de marismas, pantanos y turberas, o superficies cubiertas de aguas, sean estas de régimen natural o artificial, permanentes o temporales, estancadas o corrientes, dulces, salobres o saladas, incluidas las extensiones de agua marina cuya profundidad en marea baja no exceda de seis metros". Convención Relativa a los Humedales de Importancia Internacional especialmente como Hábitat de Aves Acuáticas, Ramsar, 2.2.1971, modificada según el Protocolo de París, 3.12.1982 y las Enmiendas de Regina, 28.5. 1987. (Consultado en http://www.ramsar.org/es/ library/field_document_type/convention-texts-554). Otra es la de Cowardin y colaboradores (1979), en donde se define como humedales "... las tierras de transición entre sistemas acuáticos y terrestres donde la columna de agua está generalmente en o cerca de la superficie o la tierra está cubierta por aguas superficiales. Los humedales deben tener uno o más de los tres atributos siguientes: (1) al menos periódicamente, la tierra sostiene predominantemente hidrófitas, (2) el sustrato es predominantemente tierra hídrica no drenada, y (3) el substrato no es suelo, y es saturado de agua o cubierto por agua superficial en algún momento durante la época de crecimiento de cada año" (en CEA-CONAMA 2006:6). Los mismos autores clasificaron a base de factores hidrológicos, geomorfológicos, químicos y biológicos en cinco sistemas principales de humedales: marinos, estuarinos, ribereños, lacustres y palustres, en el caso de RAMSAR se distinguen aquellos marinos, continentales y artificiales. Otras clasificaciones y criterios de estas se definen en CEA-CONAMA (2006:10).

4 Para la elaboración de la Figura 3 se ha utilizado un plano de Valdivia en formato digital AutoCad 2010, con curvas o cotas de nivel cada dos metros. Se han resaltado las zonas inundables, humedales, desagües y ríos en verde, mientras que en las cotas superiores o altas se ha posicionado la información entregada por Mariño de Lobera y Vivar. El sector alto que refieren los autores está ubicado en la actual calle Carlos Anwandter (Guarda, 1994:30-31, lámina 8:32). También se ha ubicado espacialmente en la Figura 3, el testimonio de Mariño de Lobera quien indica la presencia del palihue o campo de palín.

5 Aunque particularmente en la zona no se han desarrollado cronologías de incendios, sabemos por los estudios disponibles que en la región los incendios producidos por efectos volcánicos o por la ocurrencia de rayos es bastante escasa (cfr. González et al. 2014:429; Heusser 1994), por lo cual es probable que estas evidencias de incendio sean resultado de acción antrópica.

6 Los nodos o centroides sobre los cuales se diseñó la estrategia de prospección sistemática radial fueron de norte a sur: San Luis de Alba-Cruces, Valdivia-Plaza de la República, Quinchilca-Misión, Ranco-Pueblo de Lago Ranco. Los registros y densidades de sitios por $\mathrm{km}$ lineal recorrido fueron, respectivamente: $98,0,60 ; 134,1,23 ; 53,0,37 ; 118$, 0,93 (Munita 2016).

7 Relación de las Obras de Fortificación de la Plaza y Puerto de Valdivia, su dotación, gastos ocurridos y su estado. Antonio Duce. Valdivia 25 de enero de 1785. Archivo Nacional Histórico, Fondos Varios Vol. 284, fjs. 238-239v.

8 De la misma época son algunas modificaciones en la isla Teja, donde contiguo a la fábrica de ladrillos y tejas se abrió "una acequia maestra de dos a tres cuadras de largo para el desagüe de un gualve o pantano inmediato a la fábrica por cuyo medio queda libre de las inundaciones a que antes estaba expuesta". Carta de Juan Garland al Gobernador y Capitán General Antonio Guill Gonzaga, 31 de agosto de 1767. Archivo Nacional Histórico, Fondos Varios, Vol. 284: fj. 67. 
